\title{
Destinos turísticos litorales de la Costa del Sol occidental: paisaje, arquitectura y patrimonio
}

Lourdes Royo Naranjo | Dpto. Historia, Teoría y Composición Arquitectónicas. ETSA, Universidad de Sevilla

URL de la contribución <www.iaph.es/revistaph/index.php/revistaph/article/view/3951>

\section{RESUMEN}

La Costa del Sol occidental ha sido soporte de un importante crecimiento basado esencialmente en procesos de expansión turística y residencial, y desempeña hoy un papel decisivo como referente urbano en la red de ciudades medias del dominio litoral de Andalucía. Su paisaje responde como herencia a un modelo de turismo desarrollado intensamente a partir de los años sesenta, basado en la ocupación del frente costero en un continuo urbano, donde la edificación en altura y las infraestructuras compiten por la primera línea litoral.

Un ámbito territorial de gran complejidad y riqueza patrimonial donde sus municipios, pequeños pueblos pesqueros hasta los años cincuenta, han sido referentes y protagonistas de una actividad con carácter internacional representativo de una parte de nuestra historia, en paralelo al desarrollo de otros sectores, especialmente el de la agricultura intensiva y de invernadero. Una zona de las más complejas desde el punto de vista socioeconómico de toda Andalucía, posicionada al mismo tiempo como uno de los territorios más urbanizados y con un crecimiento demográfico y económico en alza constante.

\section{Palabras clave}

Arquitectura | Costa del Sol | Paisaje | Patrimonio | Turismo | 


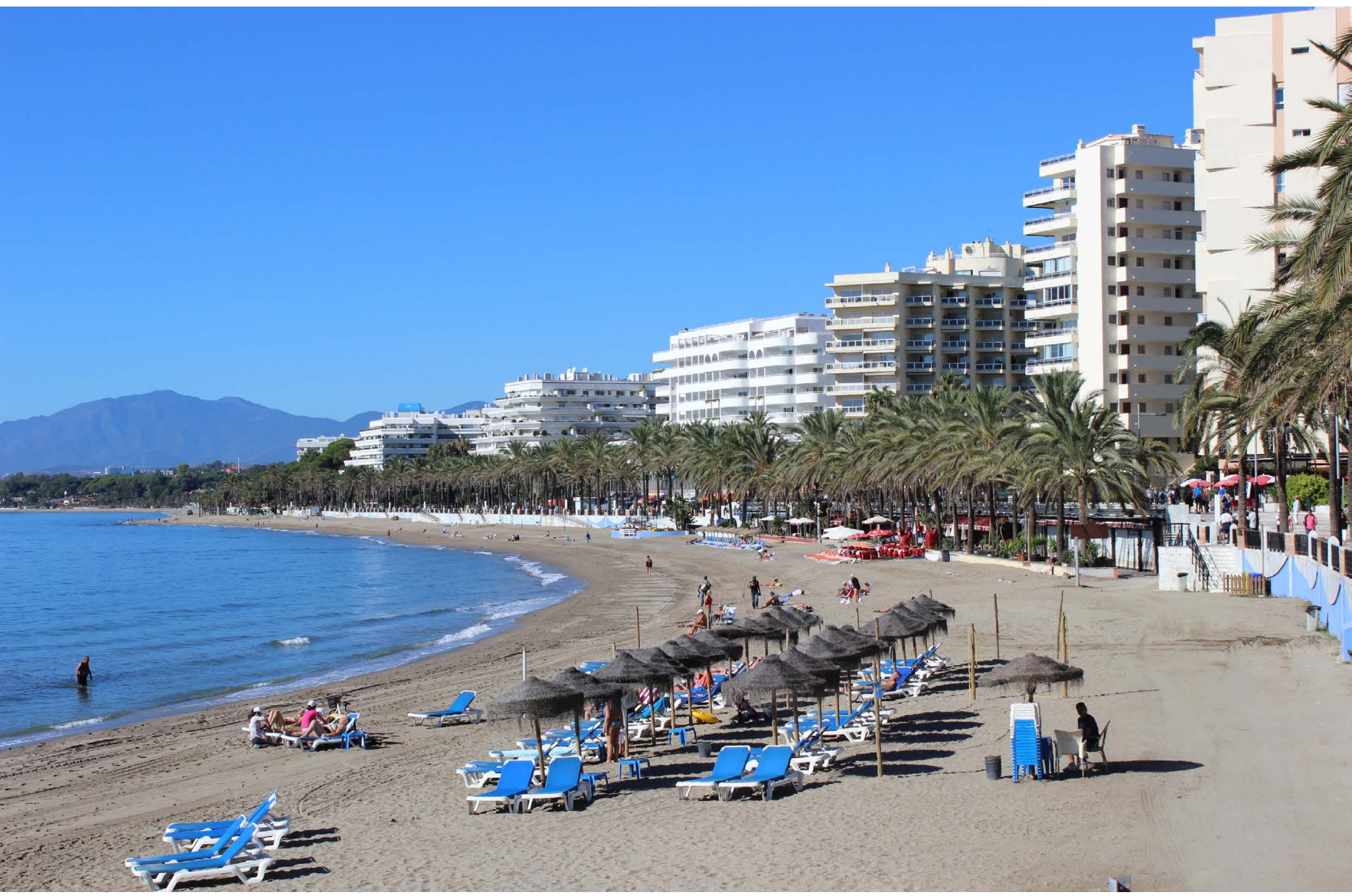

Apartamentos Skol. Marbella. 2014 | foto Lourdes Royo Naranjo, autora de todas las imágenes del artículo si no se indica los contrario 


\section{EL PAISAJE COMO REFERENTE}

Repasando las consideraciones establecidas por el Convenio Europeo del Paisaje en las que se establece que desde el punto de vista jurídico y político todo territorio es paisaje, nos detenemos en el litoral malacitano para comprobar desde este punto de vista cómo este territorio se manifiesta en la especificidad de su paisaje, al definirse no sólo como la suma de valores ecológicos y estéticos, sino como articulador de aspectos relativos a la calidad de vida de los ciudadanos, a la memoria colectiva, a la identidad local y lo que es más importante, a su valor patrimonial vinculado al territorio (ZOIDO NARANJO, 2002).

Desde este punto de vista, en nuestro discurso el paisaje se ha convertido en un elemento clave del engranaje proyectual y herramienta significativa de identidad asociada a cuestiones de referencias turísticas: "El paisaje y su diversidad, constituyen un recurso fundamental para el turismo como actividad económica en cualquier entorno o destino turístico; a su vez, éste no se muestra ajeno a los procesos de cambio que vienen determinados por la celeridad de los acontecimientos y la globalización" (sic. GALACHO JIMÉNEZ; LUQUE GIL, 1997: 26). Como consecuencia, el paisaje de la Costa del Sol, tras 50 años de actividad turística se presenta profundamente marcado por la huella del ser humano, pasando a ser más un producto de una vida urbana, que una creación natural, y en cuyos diagnósticos debemos detener nuestra mirada para reconocer desde el punto de vista patrimonial cuáles son los referentes principales con los que cuenta este territorio en sus diferentes escalas de complejidad.

\section{EL MEDIO FÍSICO COMO ARTICULADOR}

El relieve, posteriormente utilizado como recurso turístico, se constituye como pieza clave del paisaje. Tal es la situación que en la misma definición la Demarcación paisajística Málaga-Costa del Sol occidental aparece muy condicionada por la articulación de los grandes componentes naturales. La costa occidental malagueña se corresponde geográficamente con una estrecha faja territorial altamente poblada entre sierras de tamaño medio y fuertes pendientes hacia el sur donde encontramos Sierra Bermeja, Sierra Blanca, Sierra de la Alpujata, Sierra de Mijas, y el mar. En el extremo oriental, la presencia de un gran valle y el del río Guadalhorce. El resto de los ríos son de escaso trayecto, salvando importantes desniveles entre las montañas y el mar. Sólo destacan, además del citado, el Río Guadiaro y Guadalmedina, que desemboca en la misma ciudad de Málaga (AA. VV., 2010: 363).

Al mismo tiempo, el sector Costa del Sol se enmarca dentro de varias áreas: costas con sierras litorales, costas acantiladas; valles, vegas, marismas inte- 
riores y serranías de montaña media. Junto a ello, debemos mencionar el reconocimiento del alto valor ecológico con el que cuenta dicho paisaje litoral, pues nos obliga a detenernos en la identificación de varios sectores biogeoráficos configuradores de su territorio. En ellos identificamos formaciones naturales con un alto nivel de biodiversidad tanto por su flora como por su fauna, con especies de gran singularidad y alto riesgo de extinción. En el caso de la costa existe además la necesidad de preservar estos nichos ecológicos no sólo por la riqueza ambiental del lugar, sino por cuestiones estratégicas en el mantenimiento de cierta conectividad entre estos espacios naturales y distanciamiento de la fuerte presión antropológica generada por las actividades agrícolas, industriales y, fundamentalmente turísticas, evitando en este último caso las habituales conurbaciones urbana. Reconocemos así importantes recursos naturales con los que cuenta este territorio y destacamos el valor de sus paisajes, como los declarados de interés cultural en Casares y su entorno, o los espacios naturales pertenecientes a la RENPA existentes dentro de la Costa del Sol como el parque natural de Sierra de las Nieves (Istán), el paraje natural de los Reales de Sierra Bermeja (Casares y Estepona), el paraje natural de Sierra Crestellina (Casares) y el Monumento Natural de las Dunas de Artola (Marbella). De esta manera, encontramos notables presencias de un patrimonio que a lo largo del tiempo ha ido dejando su huella en el territorio litoral malacitano en forma de fortificaciones y arquitecturas militares y defensivas que se erigen en la Edad Media, torres de vigilancia desde el interior hasta la costa, villas romanas y alquerías islámicas, arquitecturas diseñadas para la producción industrial del siglo XIX o arquitecturas del XX vinculadas al ocio y el relax turísticos, entre otras.

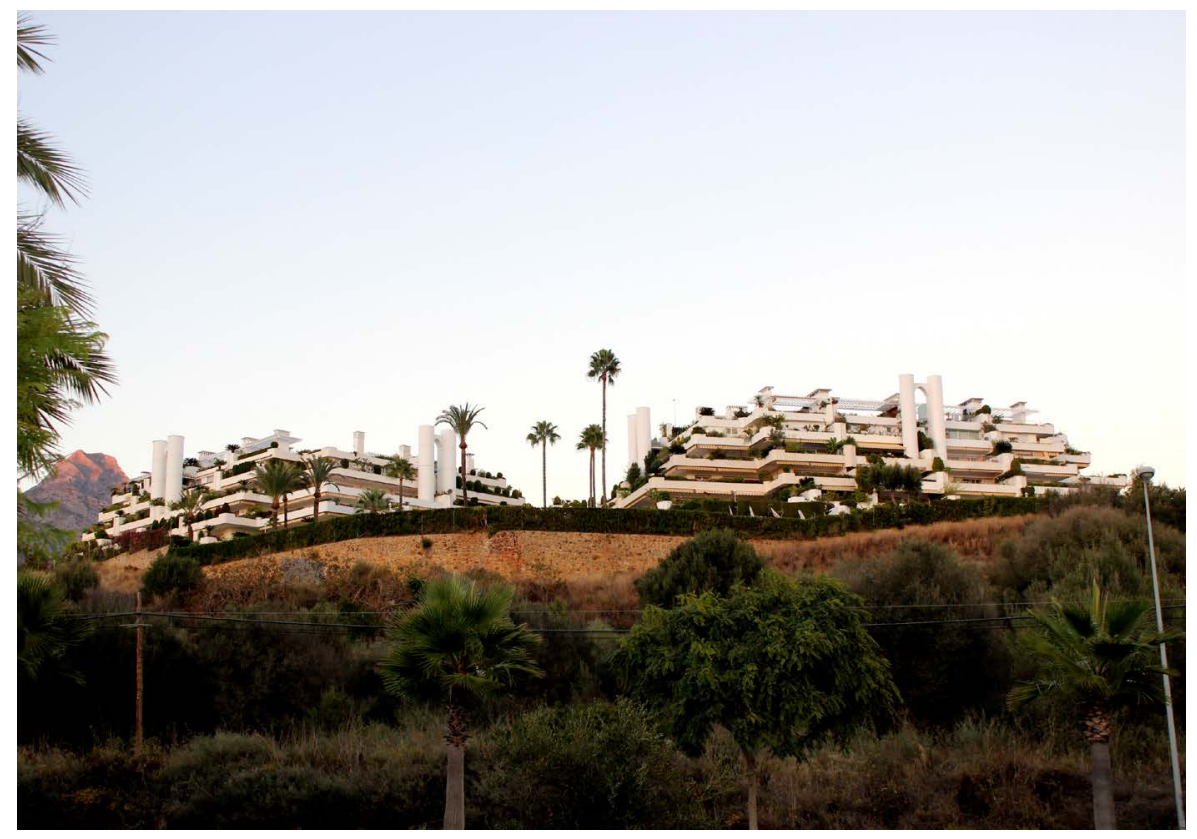




\section{HISTORIA, TURISMO Y ARQUITECTURA EN EL DISEÑO DEL PAISAJE COMO RECURSO}

En esta escala de análisis, nos acercamos a las primeras formulaciones teóricas que definieron la Costa del Sol como destino turístico de primer orden, y donde el paisaje se convirtió en el principal protagonista de una historia tanto de turistas como de inversores: "el turismo está claramente relacionado con los procesos de construcción del territorio, porque fundamenta su rendimiento económico tanto en la explotación directa del suelo como recurso para la edificación, como es un valor añadido que se incorpora a través de la cualidad que exige al medio ambiente y al paisaje. Concretamente cuando (...) se trata de especializar, diversificar y mejorar el grado de excelencia de los productos turísticos, nuevos o existentes, el paisaje vuelve a contar como elemento esencial" (BARBA; PIÉ, 1996).

La dimensión paisajística y más concretamente su valoración comienzan a incorporarse en el planeamiento territorial de manera lenta y despreocupada, con tildes pintoresquistas y de emplazamiento, y en especial, como relación de oportunidad para el proyecto de las piezas turísticas. El paso de la ciudad balnearia de Málaga al territorio turístico de la Costa del Sol generará una prolífica sucesión de planes y proyectos con efectos territoriales no muy relevantes (ESTEVE SECALL, 1982; ROYO NARANJO, 2013).

La expansión del tejido urbano en los núcleos costeros, así como la eclosión de nuevas urbanizaciones consecuencia del desarrollo económico producido por el monocultivo turístico, produjeron ensanches, reforma de interior de núcleos tradicionales, aparición de núcleos singulares fruto de iniciativas privadas, diseminación de urbanizaciones turísticas en el medio rural... provocaron como consecuencia una nueva realidad y nuevos escenarios sobre los que actuar (GALACHO JIMÉNEZ; LUQUE GIL, 1997: 49). Al mismo tiempo, heredamos un consumo de los recursos paisajísticos consecuencia del agotamiento de este discurso basado en la oferta exclusiva de sol y playa, y donde se ven afectados los elementos naturales del territorio (forestas, dunas, desembocaduras de ríos y arroyos, zonas húmedas), donde son representativas las alteraciones de la topografía preexistente o las intervenciones sobre la fachada marítima y su dinámica litoral.

\section{VALORACIÓN Y PROTECCION DE UN DESTINO LITORAL EN CLAVE PATRIMONIAL}

Sin embargo, en paralelo a la degradación del paisaje, el litoral de Andalucía ha sido objeto de numerosos planes y normas promovidos desde diferentes políticas públicas que han desarrollado figuras de protección que desde la legislación ambiental, turística, patrimonial o la planificación territorial 


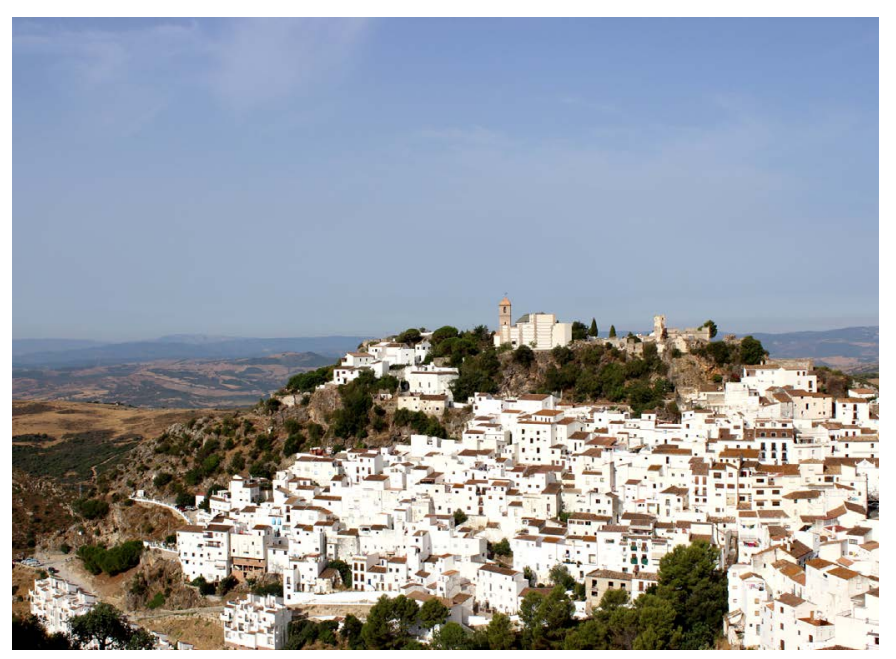

han avanzado en el reconocimiento de las cuestiones paisajísticas de la Costa del Sol Occidental y que tienen como hilo conductor la patrimonialización del litoral. Destacamos los esfuerzos recogidos en el Plan Especial de Protección del Medio Físico y Catálogo de la Provincia de Málaga (1987), las Directrices Regionales del litoral de Andalucía (1990), el Plan de Ordenación del Territorio Costa del Sol Occidental (2006), el Plan de Ordenación del Territorio de Andalucía-POTA (2006), el Plan Qualifica (2007), la propuesta de Estrategia Andaluza de Gestión Integrada de Zonas Costeras (2008), la Estrategia de Paisaje de Andalucía (2012) y el Plan de Protección del Corredor Litoral de Andalucía (2013).

La combinación de estos marcos normativos y estratégicos generan una situación peculiar. Entre los grandes dominios territoriales definidos en el POTA, el litoral es el más factible para desarrollar una política específica de paisaje que atienda a los dos ejes de acción que conlleva la misma, según el Convenio Europeo del Paisaje: la patrimonialización del carácter del paisaje, que implica un proceso de identificación, caracterización y cualificación, y la inserción de las consideraciones paisajísticas en las políticas públicas. El paisaje se convierte con todo en soporte de una estrategia de intervención al permitir, por un lado, realizar una minuciosa evaluación morfológica, patrimonial y ambiental desde la disciplina paisajística, revelando la memoria oculta específica del lugar $y$, por otro, permite trasladar las figuras de protección hacia criterios de planeamiento y diseño (PIÉ NINOT; ROSA JIMÉNEZ, 2013; GOULA; SPANOU; PÉREZ, 2012).

La Costa del Sol recicla hoy su memoria y distintos ejercicios de investigación miran con distancia y cierto desdén el origen de tan abrumador desarrollo de ocupación. Ejemplos donde la arquitectura del turismo han construido una imagen colectiva y particular de la costa ${ }^{1}$. Modelos, formulas y respuestas
Casares, 2017

Paraje natural de los Reales de Sierra Bermeja (Casares), 2017
1

Imaginario colectivo referido en películas, libros, clichés y estereotipos de una Costa del Sol reflejada en el mundo del arte, del cine y la literatura. Para más información consultar bibliografía específica adjunta al final del documento. 
2

Esta producción arquitectónica destinada al turismo en la Costa del Sol, como aproximación al hecho de la ciudad y la arquitectura turísticas integraba diversas tipologías, entre otras, edificios y complejos destinados al alojamiento temporal, urbanizaciones e inmuebles residenciales de propiedad privada, infraestructuras y equipamientos específicos o intervenciones sobre el territorio. Algunos de los ejemplos más significativos son los siguientes: en Málaga, el Hotel Málaga Palacio (1957), de Juan Jáuregui Briales, o el Edificio Luz (1967), de César Olano Gurria rán y Carlos Verdú Belmonte. En Marbella la Ciudad Sindical de Vacaciones Residencia Tiempo Libre (1956-1963), de Manuel Aymerich Amadiós y Ángel Cadarso del Pueyo; los Apartamentos Skol (1963), de Manuel Jaén Albaitero; el Hotel Meliá Don Pepe (1964), de Eleuterio Población Knnape; la Plaza de Toros de Andalucía la Nueva (1965), de Luis María de Gana y Hoyos; el Hotel Don Carlos (1967), de José María Santos Rein y Alberto López Polanco; o Torre Real (1972- 73), de Eugenio Vargas Izquierdo. En Torremolinos, el Hote Pez Espada (1959-60), de Juan Jáuregui Briales y Andrés Muñoz Monasterio; el Conjunto de apartamentos La Nogalera (1963), de Antonio Lamela Martínez; el Conjunto Playamar (1963), de Antonio Lamela Martínez; el Palacio de Exposiciones y Congresos (1968), de Rafael de la Hoz Arderius y Gerardo Olivares James. En Benalmádena, el Hotel Alay (1962 66), de Manuel Jaén Albaitero y Manuel Jaén de Zulueta. En Fuengirola, Ios Apartamentos Ópera (1964), de Andrés Escassi Corbacho. En Torre del Mar, el Club Náutico (1967), de Francisco Estrada Romero. En Casares, e Conjunto Bahía Casares (1973), de José María Santos Rein.

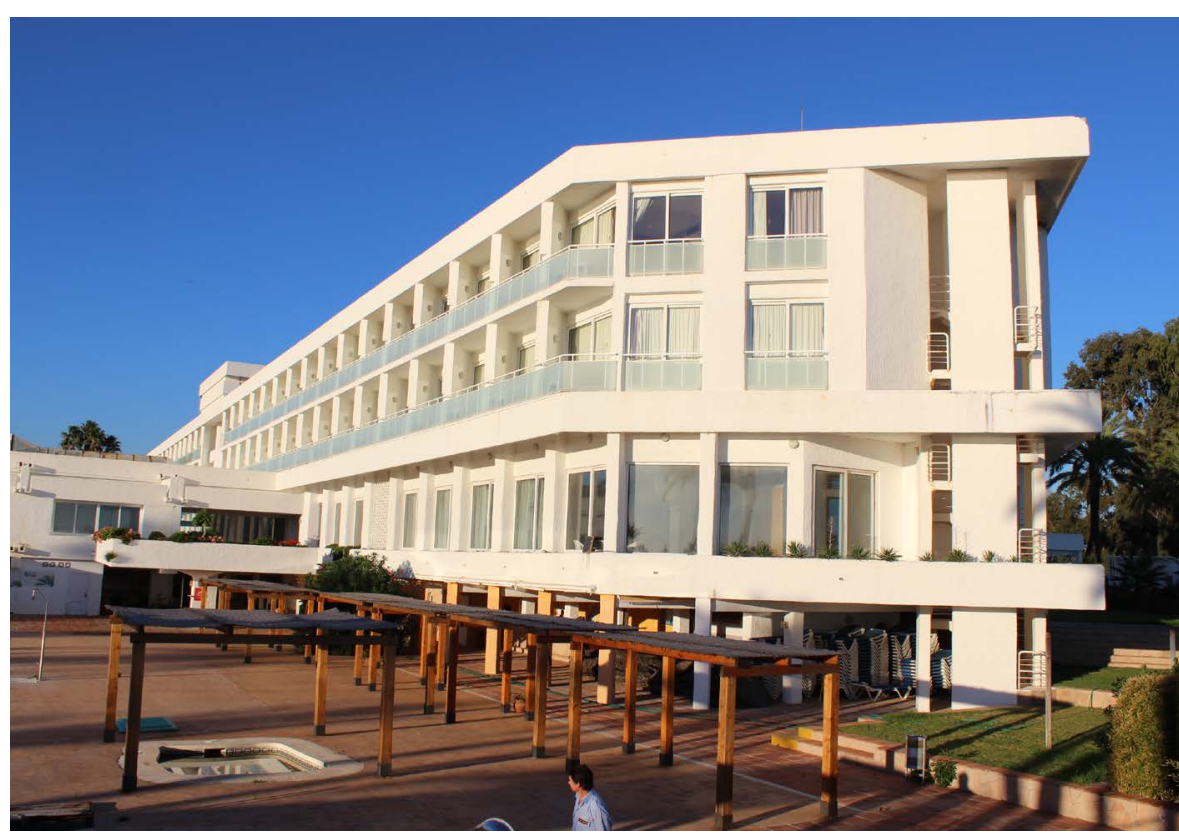

Residencia San Jaime. Estepona. 2013

arquitectónicas que se presentaron como destino internacional signo de una riqueza indiscutible del patrimonio turístico arquitectónico. Distinguir con el paso del tiempo la validez de sus fórmulas obedece no tanto a una cuestión de eficacia formal de aquellos, sino al reconocimiento de una historia imprescindible para la comprensión de la Costa del Sol, pues entendemos que en el reconocimiento de esta arquitectura turística del siglo XX se puede apreciar una apuesta dispersa, distinta, con dos velocidades y con muchas opciones, pues como es bien sabido, se permitió construir mucho y de cualquier modo. El conocimiento y valoración patrimonial de la arquitectura litoral de la Costa del Sol debe responder a esa misma complejidad y riqueza de aquellas variantes, condicionantes, impulsos constructivos y deseos de renovación. Arquitectos españoles y extranjeros, modelos importados y creados pensando en su destino con claves de modernidad configuran las piezas de este puzle ${ }^{2}$.

\section{APORTACIONES PARA LA INVESTIGACIÓN}

A día de hoy el paisaje litoral de la Costa del Sol occidental presenta grandes transformaciones consecuencia de una dinámica inmobiliaria cada vez más agresiva y con menos espacio para la actuación. La expansión del tejido urbano en los núcleos costeros ha desembocado en la configuración de una verdadera ciudad construida a lo largo de la costa. El paisaje, bien patrimonial y recurso intangible, se posiciona como pieza fundamental con el que trabajar para futuras intervenciones en el litoral. 


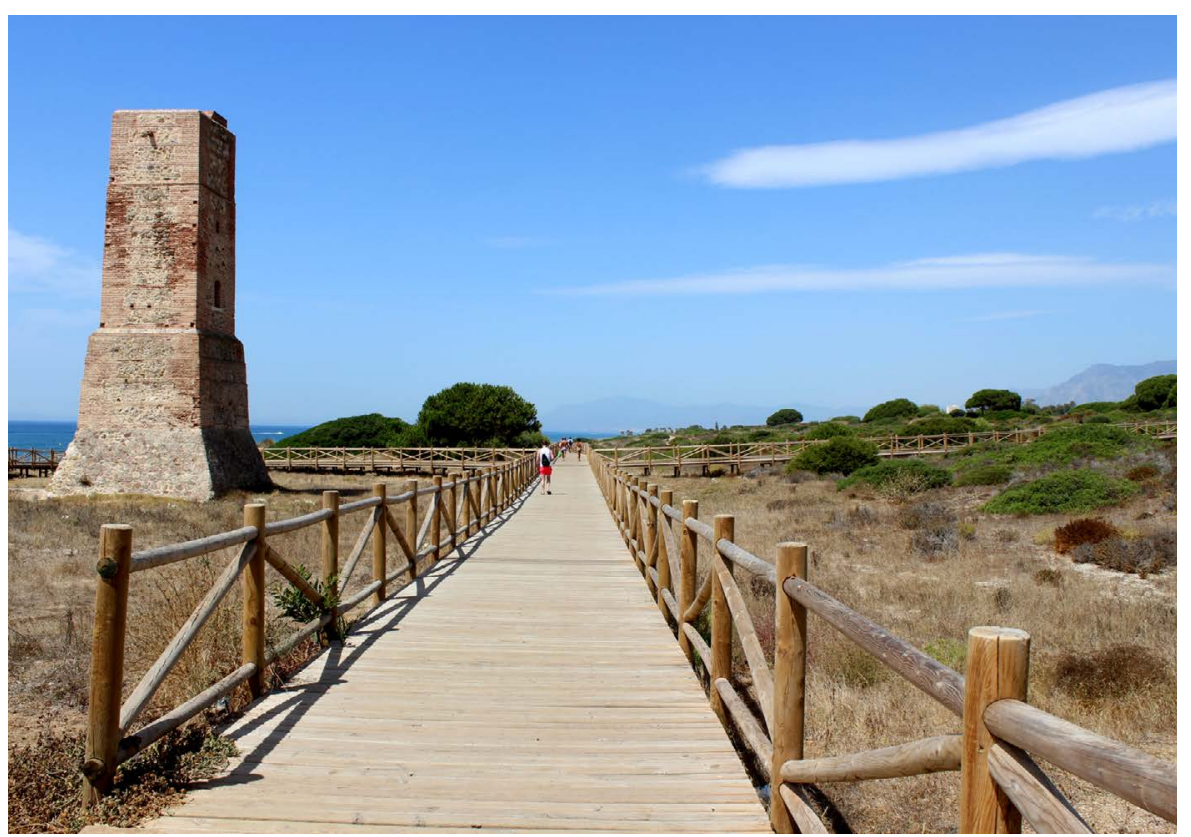

Monumento Natural Dunas de Artola. Marbella. 2017

La protección ambiental, con la delimitación y reconocimiento de piezas clave, ha sido la estrategia principal en el reconocimiento de los valores naturales, en la preservación frente a la urbanización y en el reconocimiento de las formas del paisaje. Existe también una vinculación directa entre protección ambiental y ocupación turística, ya que por un lado la presencia cercana de espacios de alto valor paisajístico nos recuerda que éstos están en el origen de la ocupación. Cuestiones que evidencian el papel que jugó la ordenación del paisaje en la construcción moderna de la Costa del Sol desde sus inicios como destino turístico. Consideración centrada no tanto en su forma como en su formación, pues no se trató tanto de preservar el paisaje, como de defender los valores paisajísticos. Esta nueva dimensión del paisaje litoral que obliga a comprenderlo como resultado de múltiples elementos no necesariamente naturales, que organizados entre sí e íntimamente ligados al territorio que los acoge, constituye una identidad propia del espacio que definimos.

Del laboratorio tipológico formulado en este período de la historia nos asombra comprobar cómo para un mismo proceso se emplearon bases comunes y soluciones muy parecidas al resto del litoral nacional. Una producción arquitectónica destinada al turismo en la costa, que como aproximación al hecho de la ciudad y la arquitectura turísticas, integraba diversas tipologías, entre otras, edificios y complejos destinados al alojamiento temporal, urbanizaciones e inmuebles residenciases de propiedad privada, infraestructuras y equipamientos específicos o intervenciones sobre el territorio, pero también arquitecturas proyectadas para el descanso y el retiro.

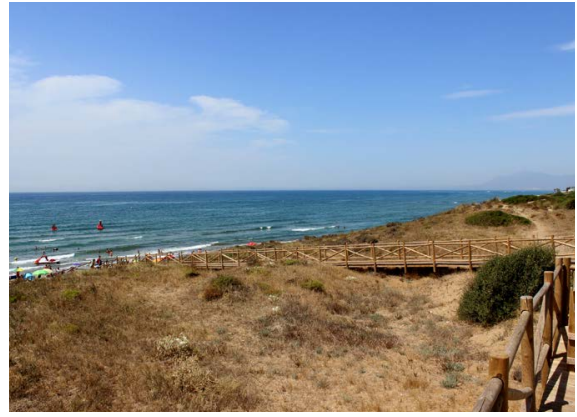

Monumento Natural Dunas de Artola. Marbella. 2017

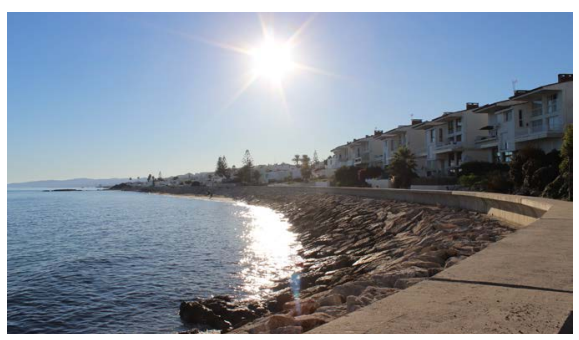

Conjunto Bahía Dorada. Estepona. 2013

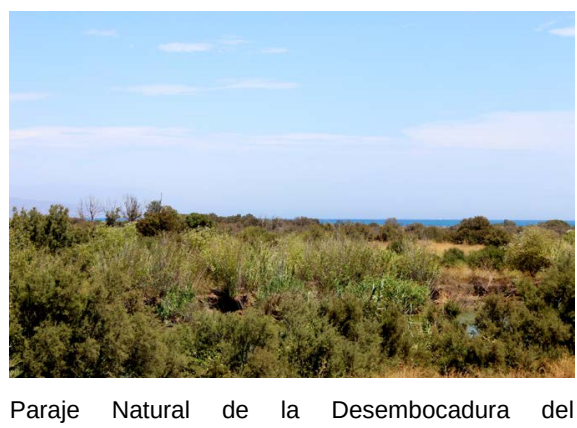
Guadalhorce. 2017

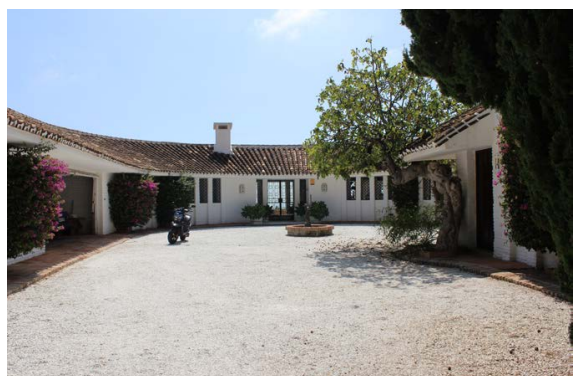

Urbanización Rancho Domingo. Benalmádena. 2013 


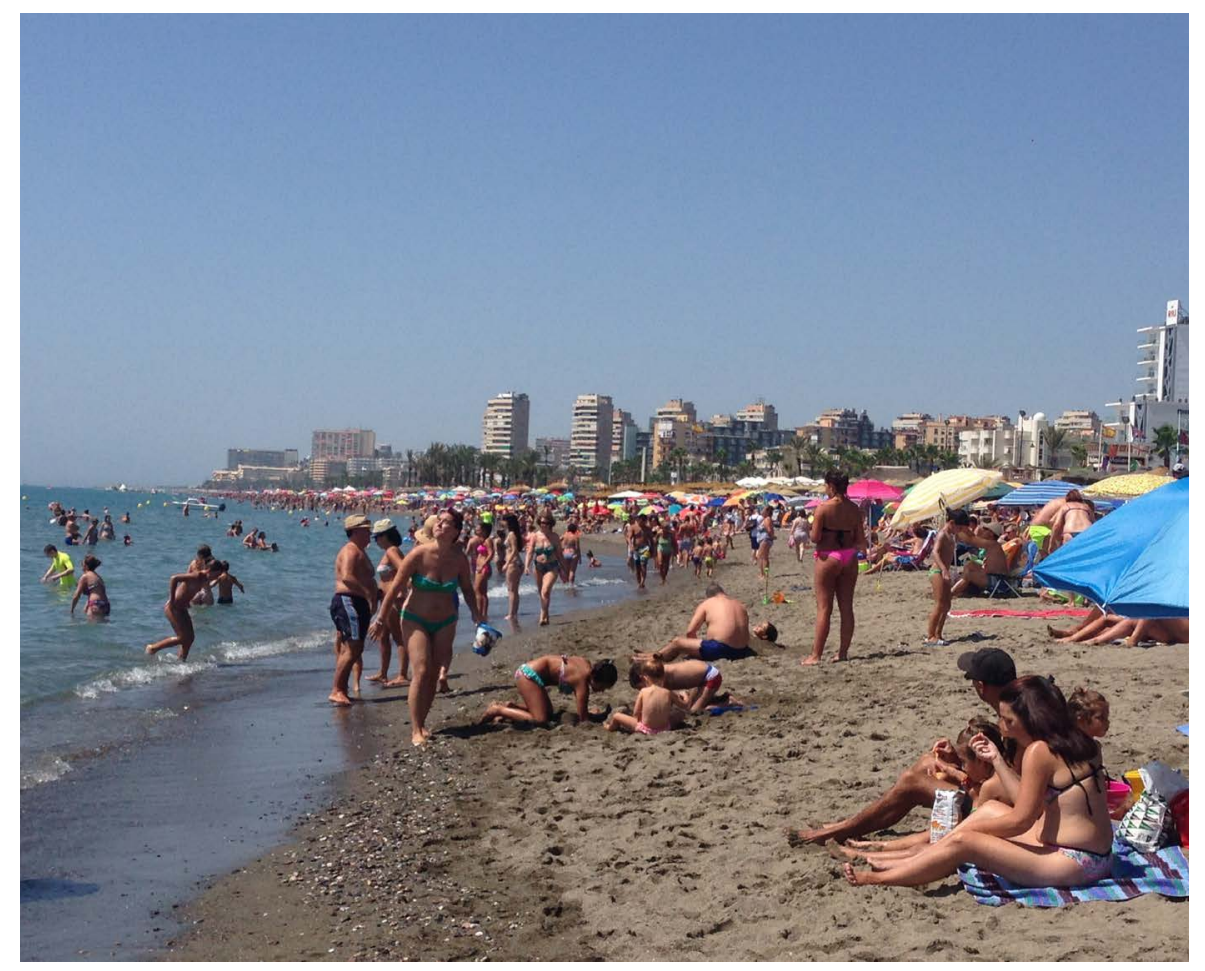

Entendemos así que la historia de la arquitectura turística debe releerse en clave patrimonial desde el mismo punto de arranque que supone el reconocimiento de esta arquitectura en la configuración histórica y territorial de la Costa del Sol. Fruto de esta situación surgiría una mezcla de estilos arquitectónicos regionalistas, organicistas, neo-mediterráneos, escasas apuestas serias por la modernidad, hoteles en altura en busca de vistas privilegiadas en primera línea de playa, urbanizaciones aisladas de tipo tradicional, complejos urbanísticos dispersos, campings en la costa y bloques de apartamentos, que con sus vistas al mar luchaban en primera línea por la rentabilidad de un suelo que se agotaba. Apuntamos aquí al reconocimiento actual de la obra proyectada por Robert Mosher en la costa de Marbella. Figura imprescindible para la historia de la arquitectura moderna no visibilizada en la historia de la Costa del Sol hasta ahora, cuyo maestro Wright incidió en el aprendizaje y cuidado del paisaje como base del proyecto arquitectónico.

El rescate y conocimiento de tales planteamientos hasta ahora no estudiados permitirían establecer nuevas líneas de investigación en torno a los elementos definidores de la costa malagueña. Del conocimiento de estos elementos, y muchas otras cuestiones patrimoniales no abordadas en el presente artículo, referimos como líneas de trabajo por las que discurrir en materia de protección sobre paisaje, patrimonio y arquitectura en los destinos turísticos litorales de la Costa del Sol occidental. 


\section{BIBLIOGRAFÍA}

- AA. VV. (2010) Paisajes y patrimonio cultural en Andalucía. Tiempo, usos e imágenes. Sevilla: IAPH, Consejería de Cultura, Junta de Andalucía, 2010, pp. 362381 (PH Cuadernos, 27)

- BARBA, R.; PIÉ, R. (ed.) (1996) Arquitectura y Turismo: Planes y Proyectos. Barcelona: Centre de Recerca i Projectes de Paisatge, CRPP, Departamento de Urbanismo y Ordenación del Territorio, UPC, 1996

- Collado SEgovia, C. (2014) Representaciones colectivas de la Costa del Sol, discursos oficiales y puntos de fuga. URBS. Revista de Estudios Urbanos y Ciencias Sociales, v. 6, n. $^{\circ} 1,2014$, pp. 35-50

- ESTEVE SECALL, R. (1982) Ocio, turismo y hoteles en la Costa del Sol. Málaga: Diputación Provincial de Málaga, 1982

- GALACHO JIMÉNEZ, F. B.; LUQUE GIL, A. (1997) La dinámica del paisaje de la Costa del Sol desde la aparición del turismo. Baética. Estudios de Arte, Geografía e Historia, Facultad de Filosofía y Letras Universidad de Málaga, 22, 1997, pp. 25-58

- GómEz ZOTANO, J. (2006) Naturaleza y Paisaje en la Costa del Sol Occidental. Málaga: Centro de ediciones de la Diputación Provincial de Málaga, 2006

- GOULA, M.; SPANOU, I; PÉREZ, P. (2012) Tour-scapes or how to convert mature tourism destinations to complex sustainable landscapes; the strategy of the "second coast". 6th Conference of the International Forum on Urbanism (IFoU): TOURBANISM, Barcelona, 25-27 enero 2012. Barcelona: riURB Editores / Universitat Politècnica de Catalunya, 2009, pp. 51-58

- HERNÁNDEZ HERNÁNDEZ, M. (2009) El paisaje como seña de identidad territorial: valorización social y factor de desarrollo, ¿utopía o realidad? Boletín de la A.G.E, n. ${ }^{\circ} 49$, 2009

- PIÉ NINOT, R. ; ROSA JIMÉNEZ, C. (2013) La cuestión del paisaje en la reinvención de los destinos turísticos maduros. Málaga y la Costa del So. ACE: Architecture, City and Environment = Arquitectura, Ciudad y Entorno, 9 (25), 2013, pp. 303-326

- ROYO NARANJO, L. (2011) La cuestión paisajística en el diseño de un territorio turístico: definición programada de la Costa del Sol en el s. XX. En Congreso: 4IAU $4^{a}$ Jornadas Internacionales sobre Investigación en Arquitectura $y$ Urbanismo, Valencia, 2011

- ROYO NARANJO, L. (2012) Valoración patrimonial en el diseño de territorios turísticos litorales. La Costa del Sol como modelo de estudio. Revista $\mathrm{PH}$ Instituto Andaluz del Patrimonio Histórico, Sevilla, n. ${ }^{\circ} 83,2012$, pp. 62-73 <http://www.iaph.es/revistaph/index.php/revistaph/article/ view/3344>
- ROYO NARANJO, L. (2013) Turismo, desarrollo, arquitectura. La aventura de la Modernidad. Sevilla: Editorial Universidad de Sevilla-Consejería de Fomento Junta de Andalucía, 2013

- ROYO NARANJo, L. (2014) Paisaje, patrimonio y arquitectura en los destinos turísticos litorales. Notas sobre la Costa del Sol. Anales de la Historia del Arte, vol. 24, 2014, pp. 253-263

- SGOTU (2014) Sistema compartido de información sobre los paisajes de Andalucía. Aplicación al litoral. Sevilla: Consejería de Medio Ambiente y Ordenación del Territorio. Junta de Andalucía, 2014

- SICA, P. (1981) Historia del urbanismo: siglo XIX. Madrid: Instituto de Estudios de Administración Local, 1981

- VILLAR LAMA, A. (2013) La mercantilización del paisaje litoral del mediterráneo andaluz: El caso paradigmático de la Costa del Sol y los campos de golf. Revista de Estudios Regionales, n. ${ }^{\circ}$ 96, 2013, pp. 215-242

- ZOIDO NARANJO, F. (2002) El paisaje y su utilidad para la ordenación del territorio. Paisajes y ordenación del territorio. Sevilla: Junta de Andalucía y Fundación Duques de Soria, 2002, pp. 20-32 